\section{Should Pharmacists Be Allowed to Conscientiously Object to Medicines Supply on the Basis of Their Personal Beliefs?}

\section{THE "PRO" SIDE}

For decades, conscientious objection has been a topic of intense debate within the sphere of professional health care, including pharmacy. Like physicians, pharmacists are bound by the same ancient yet fundamental Hippocratic principle_-dictum primum non nocere ("first do no harm") — which at times may be juxtaposed with another important ethical principle, that of respecting patient autonomy (i.e. , respect for patient dignity, self-determination, and privacy). ${ }^{1}$ The contention between these 2 major ethical principles creates what is known as an "ethical dilemma", a situation where 2 correct principles pull in opposite directions. When a health care professional objects to the wishes of a patient to avoid causing "harm" (whether for personal, spiritual, or professional reasons), this is recognized as the professional exercising his or her right to "conscientious objection." " Conscientious objection may be apparent in, though is not limited to, complex situations such as abortion, contraception, and physician-assisted suicide.

Conscientious objection is defined as follows by the Code of Ethics for Pharmacists in Australia ${ }^{3}$ :

[A] practitioner's refusal to engage or provide a service primarily because the action would violate their deeply held moral or ethical value about right and wrong.

In this situation, the $\operatorname{Code}^{3}$ places a condition on the exercise of the practitioner's right to decline supply of a medication or service. A former president of the Pharmacists Society of Australia described the limitation as follows:

However ... this right should not prevent the consumer from accessing healthcare that they are entitled to. ... Therefore in these circumstances the pharmacist should inform the consumer of the objection and appropriately facilitate continuity of care for the consumer. ${ }^{4}$

It is important to emphasize the need for continuity of care, which features in most professional codes of ethics for pharmacists around the world. When invoking one's right to conscientious objection, it remains paramount to ensure that basic professional standards are preserved. For example, like other members of a democratic society, pharmacists who have a moral objection to physician-assisted suicide arguably have the right to refuse to participate in supplying drugs used for such a procedure. Similarly, pharmacists who are fundamentally against participating in a medical action that will end a life by intention should have the freedom to respectfully invoke their right to conscientiously object to participating in such an action. However, the right to conscientious objection by no means entitles them to attempt to paternalistically influence or reject the patient's views, or diminish the patient's dignity and right to self-determination. Rather, this right is actually enacting mutual respect for each other's different perspectives, which may be resolved professionally through the process of providing continuity of care and by offering courteous, responsible, and timely referral to other access points. As described by Hanlon and others, ${ }^{5}$ the solution is in "extending the conscience clause of the code of ethics" which "would allow the efficient provision of the pharmaceutical service whilst at the same time respecting the personal beliefs of those who object to cooperating in the taking of a human life."

One way to minimize the complexities of managing pharmacists' right to conscientious objection is to initiate an "opt-in" registration system, a process whereby pharmacists who are willing to supply the medication can register to do so. ${ }^{6}$ Such a system is already used for the supply of the abortion medications mifepristone and misoprostol in Australia. The abortifacient combination medication MS-2 Step (MS Health Pty Ltd)previously known as RU486-is available from community pharmacies that have been nominated by and are in agreement with a certified medical practitioner. ${ }^{7}$ To dispense MS-2 Step, a pharmacist must be registered, must ensure that the prescriber is a certified physician, and must confirm that the procedure has been fully explained to and a consent form signed by the patient.

It is also important to consider the benefits of having health care providers who are morally driven and who are willing to validate their moral integrity through conscientious practice of health care provision. Conscientiously practising professionals can signal an interface of advocacy in complex situations and can reduce the risk of conforming with professional pressures that may occur in hierarchical structures within health care fields. ${ }^{8,9}$

The notion of the right of the health carer to conscientious objection is contested by some. For example, Savulescu and Schuklenk ${ }^{10}$ have stated "there should be better protections for patients from doctors' personal values and there should be more severe restrictions on the right to conscientious objection, particularly in relation to assisted dying." Eliminating individuals' 
right to choose not to participate in an action they find morally confronting, irrespective of their occupation, is a form of conformism, toeing the line of contemporary notions of consumer protection and the influential shift toward empowering patients' right to self-determination. Yet denying providers their right to conscientious objection constitutes a breach of the fundamental human rights that make up the fabric of a democratic society.

Forcing a health care provider to perform and participate in practices to which they object on moral or ethical grounds could instigate subadequate care, which could in turn lead to suboptimal outcomes for patients. Individuals forced to enact a task to which they feel morally or ethically opposed tend to do so reluctantly, with instinctive apathy, functioning at a suboptimal level. Instead, allowing patients to receive care from health care professionals who are willing and not conflicted by their conscience will ensure more favourable patient outcomes and patient care. For the most part, conscientious objection is accepted in pharmacy and the wider medical world, so long as the patient is redirected to appropriate alternative channels of help.

The right to self-determination should be enjoyed by all humans, allowing for a freedom of thought and conscience for each and every individual. However, as pharmacists we should exercise our professional right to conscientious objection responsibly_without harassment, paternalism, or discrimination. The stakeholders involved, including patients themselves, may have various views on what they consider to be the best decision for the patient. It is imperative, however, that all parties respect the others' right to voice their opinions and follow their conscience, with the ultimate intention of providing patients with health care services best suited to their needs.

\section{References}

1. Hippocrates. The history of epidemics. Farr S, translator. London (UK): T Cadell; 1780.

2. Code of conduct for pharmacists. Melbourne (Australia): Pharmacy Board of Australia; 2014.

3. Code of ethics for pharmacists. Deakin (Australia): Pharmaceutical Society of Australia; 2017.

4. Pharmacists and conscientious objection to supply of the oral contraceptive pill [media release]. Deakin (Australia): Pharmaceutical Society of Australia; 2014 Feb 14 [cited 2018 Mar 19]. Available from: https://www.psa.org.au/ media-releases/2014-releases/pharmacists-and-conscientious-objection-tosupply-of-the-oral-contraceptive-pill

5. Hanlon TRG, Weiss MC, Rees J. British community pharmacists' views of physician-assisted suicide (PAS). J Med Ethics. 2000;26(5):363-9.

6. Lee RY, Moles R, Chaar B. Mifepristone (RU486) in Australian pharmacies: the ethical and practical challenges. Contraception. 2015;91(1):25-30.

7. Petersen KA. Early medical abortion: legal and medical developments in Australia. Med J Aust. 2010;193(1):26-9.

8. Birchley G. A clear case for conscience in healthcare practice. J Med Ethics. 2012;38(1):13-7.

9. Morton NT, Kirkwood KW. Conscience and conscientious objection of health care professionals refocusing the issue. HEC Forum. 2009; 21(4):351-64.

10. Savulescu J, Schuklenk U. Doctors have no right to refuse medical assistance in dying, abortion or contraception. Bioethics. 2017;31(3):162-70.
Sami Isaac, BPharm(Hons), MPS

$\mathrm{PhD}$ candidate

Betty Chaar, BPharm, PhD, MHL

Senior Lecturer and Supervising Academic

The University of Sydney

Camperdown, New South Wales, Australia

Competing interests: None declared.

\section{THE "CON" SIDE}

Patients should have access to any legal medical service for which they meet the criteria, including the service being plausibly in their interests. Whether patients decide to use this access is up to them.

Patients may refuse treatment on moral or religious grounds. For example, Jehovah's Witnesses refuse blood transfusions according to religious belief. These choices may lead to health costs for the patient. It has long been established that the role of health care professionals does not include imposing their judgment onto their patients, but should health care professionals have their own moral and religious beliefs that conflict with those of the patient, conscientious objection allows the professionals to opt out of providing the treatment.

Conscientious objection pits the caregiver's moral beliefs against the patient's access to medicine. There are 2 common regulatory frameworks allowing conscientious objection. The first is to prioritize patient access within the framework for objection, by requiring referral. This is problematic in 2 possible ways. First, it does not succeed in preserving patient access. As an example, consider the "morningafter pill". About 5\% of Ontario pharmacists are unwilling to stock the morning-after pill, ${ }^{1}$ and about $60 \%$ of rural Canadians live further than $5 \mathrm{~km}$ from their nearest pharmacy. ${ }^{2}$ If contraception failure occurs on a Friday night, a woman may find that her pharmacy is one of the $15 \%$ of rural pharmacies that are closed on weekends. ${ }^{1}$ If the nearest open pharmacy is among the 1 in 20 that refuse to stock the drug, it is a still longer journey to a third pharmacy. Patients face a variety of practical barriers to gaining access to medication, including having only short breaks from work, lack of a private car, and difficulties paying travel costs. If a medicine cannot be accessed by a real-life patient within its window of efficacy, the end result is no different, from the patient's perspective, from what would occur if the medicine were banned entirely. There are also more insidious barriers to access: if a patient faces shame and humiliation in her quest for legal health care services, the health care system has failed her.

The second problem with the requirement for referral (as many proponents of conscientious objection also point out) is that this framework does not really remove the professional from involvement. Pharmacists may object to dispensing certain types of birth control or drugs for euthanasia. In neither case will they actually administer the drug; another intervening agent will do that. However, adding 
one more step to this process - by referring the patient to another agent who the pharmacist knows will dispense the drug —-makes little moral difference.

In the second framework for conscientious objection, transfer of care is required only if the patient actively requests it. ${ }^{3}$ This does little more than shift the balance further against the patient who is accessing the treatment. If the patient does request a transfer of care, the pharmacist must comply, once more putting the objector only a little further along in the chain of agents than was already the case. For the policy to relieve the objector of any involvement would require that the patient not request the transfer of care. This framework uses patient vulnerability to nudge patients away from accessing health care to which they are entitled. Patients may be unaware of their right, or may be too afraid or ashamed to request it. Patient health literacy has been found to have a significant influence on the use of health services. ${ }^{4}$ This framework for conscientious objection exploits the existing link between poor patient health literacy and reduced use of health services by putting the onus on patients to prompt the professional to offer a transfer.

Refusing to allow conscientious objection does not imply that the grounds for such objection are unreasonable. Consider the following hypothetical case. Emma, a pharmacist for 10 years, decides to become a committed vegan because she has come to believe that animals have equal moral status to humans. This is a very defensible ethical position..$^{5}$ At work, while dispensing a codeine prescription, she realizes that the hospital's entire stock of this drug contains lactose, an animal product. Most would agree that, however strongly held and rational Emma's beliefs are, she should still dispense the medication.

It would be reasonable for Emma, as a patient, to refuse to take her own medication if it contained animal products, even if such refusal meant compromising or delaying her medical treatment; however, it would not be reasonable for Emma, as a pharmacist, to impose her beliefs on her patients.

When should a health care professional take a stand? Two situations come to mind: if a health care professional is asked to do something to which the competent patient does not consent (as was the case for the nurse who refused to force-feed prisoners in Guantanamo Bay) ${ }^{6}$ or if there is no reasonable basis on which the treatment could be ethically sound. In both of these situations, the health care professional should object, but the objection is not against that individual being asked to undertake the duty, but rather is an objection to the patient being subjected to the treatment at all. This is a more demanding position that cannot be satisfied by conscientious objection frameworks.

There is reasonable ethical disagreement over abortion and euthanasia: that is, while those who disagree with these medical actions are reasonable, there are also reasonable ethical arguments in their favour. Not allowing conscientious objection in Emma's case does not depend on her belief being definitively unreasonable, even though many would in fact disagree with her. The principle still stands when it is a matter of human life and death. To take another example, there is reasonable ethical disagreement over distributive justice, the question of which patients should be prioritized when resources (such as organs) are limited and which should inevitably die. Nevertheless, a doctor is expected to follow agreed policies and procedures to assign an organ to a particular patient, even if the doctor's strongly held ethical belief was that the organ should go to another patient.

Values enshrined in law should be debated and reviewed. Health care professionals should of course engage with these issues and participate in such discussions. At the same time, patients have a right to access a certain range of medical interventions from their doctor or pharmacist, when those professions hold a monopoly over the provision of those interventions. But there is no inherent right for an individual to become a pharmacist or an obstetrician or a general practitioner. If the job does not suit, other specialties are available.

Ultimately, there is a balance to be found. Today, pharmacists and doctors can reasonably expect to be able to conscientiously object because the law allows them to do so. They have invested time and money in their training under this belief. But there is no good reason to allow conscientious objection for those now entering the profession. Sweden and Finland have no legal right of conscientious objection and have no problem supplying excellent doctors and pharmacists to the community. It would be better both for the professional and for the patient if those unwilling to provide all the services over which a profession has a monopoly were prevented from entering that profession.

So, the answer would seem to be to change the rules and allow into pharmacy school only those who are willing to dispense the medications necessary for birth control, voluntary euthanasia, and other legal treatments. Those who morally object to roles within that profession may choose another profession or another branch of the same profession, one where they can prioritize the needs of their patients with a clear conscience.

\section{References}

1. Dunn S, Brown TER, Alldred J. Availability of emergency contraception after its deregulation from prescription-only status: a survey of Ontario pharmacies. CMAJ. 2008;178(4):423-4.

2. Law MR, Dijkstra A, Douillard JA, Morgan SG. Geographic accessibility of community pharmacies in Ontario. Healthc Policy. 2011;6(3):36-46.

3. How does conscientious objection work in pharmacy practice? Vancouver (BC): College of Pharmacists of British Columbia; [cited 2018 Mar 19]. Available from: www.bcpharmacists.org/faq/how-does-conscientious-objection-workpharmacy-practice

4. Saha S, Arbelaez JJ, Cooper LA. Patient-physician relationships and racial disparities in the quality of health care. Am J Public Health. 2003;93(10):1713-9.

5. Singer P. Animal liberation. New York (NY): Harper Collins; 1975.

6. Savulescu J, Schuklenk U. Doctors have no right to refuse medical assistance in dying, abortion or contraception. Bioethics. 2017;31(3):162-70.

Julian Savulescu, MBBS, BMedSc, PhD

Oxford Uehiro Centre for Practical Ethics

University of Oxford

Oxford, United Kingdom

Competing interests: The author's work on this manuscript was supported by Australian Research Council grant DP150102168, with salary support from the Uehiro Foundation on Ethics and Education. No other competing interests were declared. 